\title{
Pancreatic hypertrophy with acinar cell nodules after longterm fundectomy in the rat
}

\author{
M Chu, L Franzén, S Sullivan, S Wingren, J F Rehfeld, K Borch
}

\begin{abstract}
The effect of gastric fundectomy with hypergastrinaemia on the pancreas in rats was studied for 14 months. Rats with hypercholecystokininaemia that had had a pancreaticobiliary diversion (PBD) operation and sham operated rats served as controls. Fundectomised rats showed a significant increase in pancreatic weight and total DNA and protein content compared with sham operated rats. DNA flow cytometry showed a significantly higher ratio of tetraploid to diploid nuclei in pancreatic tissue after fundectomy than after sham operation. Mean values of all these variables were significantly lower after fundectomy than after PBD. Acidophilic atypical acinar cell foci of the pancreas were diagnosed in both fundectomised and PBD operated rats, but not in sham operated controls. The volume density and ${ }^{3} \mathrm{H}$-thymidine labelling index of the acidophilic atypical acinar cell foci were significantly lower after fundectomy than after PBD. Changes consistent with pancreatic adenoma were diagnosed in the PBD group only. In conclusion, fundectomy lasting about half of the life span in rats causes pancreatic hyperplasia and hypertrophy, as well as development of acidophilic atypical acinar cell foci. Although hypergastrinaemia is a prominent feature, it may not be the only factor responsible for this pancreaticotrophical effect of fundectomy. (Gut 1993; 34: 988-993)
\end{abstract}

Gastrin-17 and pentagastrin given exogenously, as well as surgical procedures leading to endogenous hypergastrinaemia, have been reported to stimulate growth of the exocrine pancreas in mice and rats. ${ }^{1-6}$ Gastrin receptors have been found in guinea pig pancreatic acini ${ }^{7}$ and in an azaserine induced rat carcinoma cell line. ${ }^{8}$ It has been shown in man that gastrin-17 augments pancreatic enzyme secretion at doses that are below the maximum for gastric acid secretion. ${ }^{9}$ These findings show that gastrin, under certain circumstances, may stimulate growth and function of the exocrine pancreas. There are other studies, however, showing that neither potent acid secretion inhibition with hypergastrinaemia in different rodents, ${ }^{1011}$ nor gastrin17 infusion in rats, ${ }^{12}$ causes pancreatic growth.

In rats, resection of the oxyntic gland area of the stomach (fundectomy) induces endogenous hypergastrinaemia. ${ }^{13}{ }^{14}$ This model has been used to evaluate the effects of chronic hypergastrinaemia on digestive organs, including the pancreas. In one study, fundectomy for 10 weeks did not induce pancreatic hypertrophy. ${ }^{14}$ The effect of fundectomy for longer than 10 weeks on the pancreas is not known. The purpose of this study was to investigate this aspect using simultaneous measurements of morphology, DNA ploidy, and autoradiography.

Pancreaticobiliary diversion (PBD) in the rat and hamster induces persistent hypercholecystokininaemia with pancreatic hypertrophy. ${ }^{15-17}$ This trophic effect can be prevented by the simultaneous administration of a cholecystokinin (CCK) receptor antagonist namely L-364,718. ${ }^{18} 19$ In rats, longterm PBD leads to the development of hyperplastic acinar cell nodules and adenoma in the pancreas. ${ }^{2021} \mathrm{We}$ therefore decided to include this model as a positive control in this study.

\section{Methods}

\section{ANIMALS AND STUDY DESIGN}

The study was approved by the local animal welfare committee. Forty two male eight week old Wistar rats (Bantin and Kingman, United Kindom) with a mean body weight (SD) of 268 (21) $\mathrm{g}$ were used. The animals were kept at $20^{\circ} \mathrm{C}$, $50 \%$ humidity and a light/dark cycle of $12 / 12$ hours. They had free access to standard rat food pellets (EWOS, Sweden) and tap water. Rats were divided into three groups. One group $(\mathbf{n}=$ 14) was operated on with resection of the oxyntic gland area of the stomach (fundectomy). The vagal trunks were preserved, and gastric function was restored by anastomosis between the antrum and the non-oxyntic rumen of the proximal stomach. ${ }^{14}$ Another group $(n=16)$ had $\mathrm{PBD}^{16}$ by transposing, at most, $7 \mathrm{~mm}$ of duodenum, including the pancreaticobiliary ducts and papilla, to the middle of the small intestine. The third group $(n=12)$ was sham operated with small intestinal transection and gastrotomy in the oxyntic gland area. Ketamine hydrochloride (Ketalar, Parke-Davis, United Kingdom) and xylazin chloride (Rompun, Bayer, Germany) given intraperitoneally were used for general anaesthesia. Animals were fasted for 15 hours before the operation. Postoperative fasting lasted 24 hours during which the animals received two subcutaneous injections of $8 \mathrm{ml} 0.9 \%$ saline. There was no early postoperative death, but one fundectomised rat died 10 months after the operation.

At 14 months, all rats were killed by exsanguination under general anaesthesia and after fasting for 15 hours. One hour before being killed, each rat received ${ }^{3} \mathrm{H}$-thymidine through the internal jugular vein (specific activity $20.0 \mathrm{Ci}$ / mmol, Du Pont de Nemours GmbH, Germany) in a dose of $1 \mu \mathrm{Ci} / \mathrm{g}$ body weight. To rule out the possible influence of intraperitoneal sequelae of the operation, only animals with no or slight 
adhesions in the area of the operation were included. This resulted in 10 fundectomised, 13 PBD operated, and 10 sham operated rats for further studies. The entire pancreas was removed, trimmed of fat, and weighed. The presence of macroscopic nodules was noted and their diameter recorded. The pancreatic tail was removed and fixed in formalin for histological studies. A piece of tissue adjacent to the pancreatic tail was excised and kept in citrate buffer at $-70^{\circ} \mathrm{C}$ for flow cytometry..$^{22}$ The rest of the gland was quick frozen and stored at $-70^{\circ} \mathrm{C}$ for DNA and protein analysis. Blood samples of the fasted state of the rats were taken at the time when the animals were killed for measurement of gastrin and CCK in plasma and were collected in EDTA tubes from the internal jugular vein. Plasma was stored at $-20^{\circ} \mathrm{C}$ until analysed.

\section{DNA AND PROTEIN ANALYSIS}

Pancreatic tissue DNA and protein contents were analysed according to the methods described by Labarca and Paigen ${ }^{23}$ and Lowry $e t$ al,${ }^{24}$ respectively.

Flow cytometry was performed blindly. The tissue was thawed and dissected with a pair of scissors at room temperature. For preparation of nuclei suspension, a detergent trypsin procedure specified by Vindeløv et $a l^{22}$ was used. The trypsinised nuclei, which were stabilised by spermine tetrahydrochloride, were stained with propidium iodide after filtration. A FACscan flow cytometer (Becton Dickinson) and a $15 \mathrm{~mW}$ argon laser ( $488 \mathrm{~nm}$ ) were used to estimate DNA ploidy and $S$ phase fraction. Histograms with at least 15000 events were recorded. Chicken and trout red blood cells were used as internal reference standards..$^{25} \mathrm{~S}$ phase was calculated using a rectangular distribution. ${ }^{26}$ The number of channels between the $G_{0} / G_{1}$ and $G_{2} / M$ peak were multiplied by the mean number of cells in the channels interactively selected in the $S$ phase region of the histogram.

AUTORADIOGRAPHY AND HISTOLOGICAL ANALYSIS For autoradiographical and morphological studies, tissue specimens fixed in $4 \%$ buffered formalin were embedded in plastic (JB4 Kit, Polaron Equipment, Watford, United Kingdom) and cut in $2 \mu \mathrm{m}$ thick sections. These were coated with Kodak $\mathrm{NTB}_{2}$ emulsion (Eastman Kodak, NY, USA), developed after four weeks of incubation in darkness at $4^{\circ} \mathrm{C}$, and counterstained with haematoxylin and eosin. Atypical acinar cell foci were identified histologically and classified as acidophilic or basophilic according to established criteria. ${ }^{27}$ Identification of pancreatic adenoma or carcinoma was also made according to previously described criteria. ${ }^{28} 29$ Sections from the pancreatic tail were screened for such lesions.

The volume density (\%) of atypical acinar cell foci was determined blindly with a modified point counting method, ${ }^{30}$ using a magnification of $\times 400$ and $25 \mu \mathrm{m}$ between the points. In each animal, a total of 30000 points were counted over consecutive visual fields across the tissue sections. The ${ }^{3} \mathrm{H}$-thymidine labelling index of the atypical acinar cell foci was determined blindly on autoradiographed sections with a magnification of $\times 1000 .{ }^{27}$ Five or more grains overlying a nucleus were considered a significant labelling. In each animal, a total of 200 labelled and non-labelled acinar cell nuclei within the foci were counted in consecutive visual fields. Labelling index was expressed as the number of labelled cells per 1000 cells. The diameter of the foci was determined microscopically, taking the mean of at least two measurements.

\section{PLASMA GASTRIN AND CHOLECYSTOKININ ASSAY}

The concentrations of gastrin in plasma were measured by a specific radioimmunoassay, as previously described. ${ }^{31} 32$ The concentrations of CCK in plasma were measured by a radioimmunoassay using C-terminal directed antiserum samples without cross reactivity towards gastrin. ${ }^{33}$ The assays have been described in detail elsewhere. ${ }^{3435}$

\section{STATISTICAL ANALYSIS}

Results are expressed as mean (SEM). Two tailed Student's $t$ test as well as the MannWhitney $U$ test were used. Differences were considered significant when $\mathrm{p}<0.05$ in both tests. p Values are those derived from the $t$ test unless otherwise stated.

\section{Results}

BODY WEIGHT AND PLASMA GASTRIN AND CHOLECYSTOKININ

The animals seemed healthy during the experiment. At the time of death, the mean body weight of the fundectomised rats was $80 \%$ of that in the sham operated rats, while the corresponding figure in PBD operated rats was $96 \%$ (Table I). Figure 1 shows the fasting plasma concentrations of gastrin and CCK at the time of death.

TABLE I Mean (SEM) of the body weight (BW), pancreatic weight (PW), ratio of pancreatic weight to body weight (PW/ $B W)$, total pancreatic protein, total pancreatic DNA, and the ratio of tetraploid to diploid nuclei $(T / D)$ in pancreatic tissue 14 months after fundectomy, pancreatobiliary diversion $(P B D)$, and sham operation (control) in the rat.

\begin{tabular}{|c|c|c|c|c|c|c|c|}
\hline Groups & Animals & $B W(g)$ & $P W(m g)$ & $\begin{array}{l}P W / B W \\
(m g / g)\end{array}$ & $\begin{array}{l}\text { Protein } \\
(m g)\end{array}$ & $D N A(m g)$ & $T / D$ \\
\hline $\begin{array}{l}\text { Control } \\
\text { Fundectomy } \\
\text { PBD }\end{array}$ & $\begin{array}{l}10 \\
10 \\
13\end{array}$ & $\begin{array}{l}591(22) \\
470(32)^{\star \star} \\
583(16)^{\mathrm{NS}}\end{array}$ & $\begin{array}{l}1147(42) \\
1505(46)^{\star \star \star} \\
2774(126)^{\star \star \star}\end{array}$ & $\begin{array}{l}2 \cdot 0(0 \cdot 1) \\
3 \cdot 3(0 \cdot 2)^{\star \star \star} \\
4 \cdot 8(1 \cdot 2)^{\star \star \star}\end{array}$ & $\begin{array}{l}137(5) \\
202(10)^{\star \star \star} \\
355(20)^{\star \star \star}\end{array}$ & $\begin{array}{l}6 \cdot 7(0 \cdot 2) \\
12 \cdot 2(0 \cdot 7)^{\star \star \star} \\
16 \cdot 9(1 \cdot 3)^{\star \star \star}\end{array}$ & $\begin{array}{l}0.108(0.016) \dagger \\
0.212(0.038)^{\star} \\
0 \cdot 360(0.049)^{\star \star}\end{array}$ \\
\hline
\end{tabular}

NS = not significant, ${ }^{\star} \mathrm{p}<0.05,{ }^{\star \star} \mathrm{p}<0.01,{ }^{\star \star} \mathrm{p}<0.001$ when compared with the controls and according to two tailed Student's $t$ test. †No of rats $=7$. 


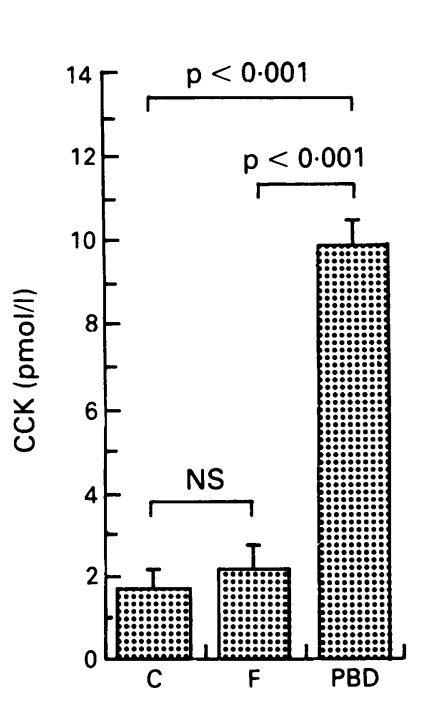

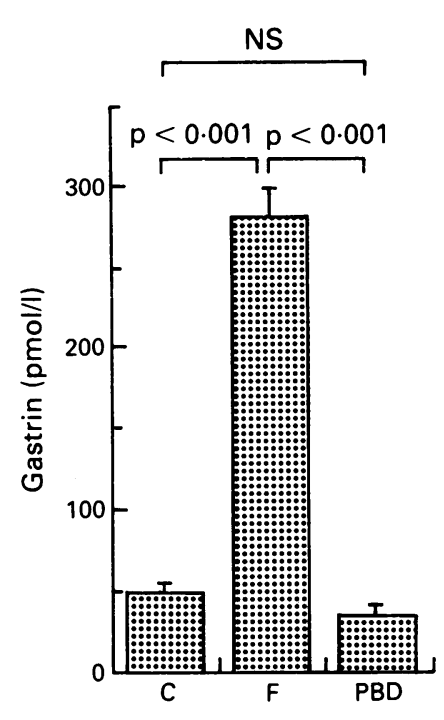

Figure 1: Mean and SEM of the fasting plasma gastrin and cholecystokinin (CCK) concentrations in groups of sham operated $(C)(n=9)$, fundectomised $(F)(n=10)$, and pancreaticobiliary division operated $(P B D)(n=12)$ rats 14 months after the operation. ( $p$ Values are from two-tailed Student's $\mathrm{t}$ test, $N S=$ not significant).

\section{PANCREATIC WEIGHT, PROTEIN, AND DNA} CONTENT

The mean pancreatic weight was increased by $31 \%$ in the fundectomy group and by $142 \%$ in the PBD group, compared with the sham operated group (Table I). Correspondingly, the relative pancreatic weight (mg pancreas per $\mathrm{g}$ body weight) was increased by $65 \%$ after fundectomy and by $140 \%$ after PBD. The mean total pancreatic content of protein and DNA was increased by $47 \%$ and $82 \%$, respectively, in the fundectomy group, and by $159 \%$ and $152 \%$, respectively, in the PBD group (Table I). All these increases were statistically significant, as were the differences between fundectomised and PBD operated animals $(\mathrm{p}<0.001, \mathrm{p}<0.001$, $\mathrm{p}<0.001, \mathrm{p}<0.005$, respectively).

\section{DNA PLOIDY}

There was a significant increase in the ratio of tetraploid to diploid nuclei in pancreatic tissue in both fundectomised and PBD operated animals, when compared with the sham operated controls (Table I). The ratios were higher in the PBD group than in the fundectomy group $(\mathrm{p}<0.04)$. The fraction of cells in $S$ phase did not differ significantly between the groups. Figure 2 shows representative DNA flow cytometry histograms.

MACROSCOPICAL AND MICROSCOPICAL FINDINGS Multiple nodules with a maximum diameter of $1 \mathrm{~mm}$ were seen on macroscopical examination on the surface of two of 10 pancreases in the fundectomy group, and on four of 13 pancreases in the PBD group. Nodules with a maximum diameter of $3 \mathrm{~mm}$ were seen on three of the 13 pancreases in the PBD group only. No nodules were seen in the sham operated animals.

Acidophilic atypical acinar cell foci were diagnosed by microscopical examination in four $(40 \%)$ of 10 animals in the fundectomy group and in $11(85 \%)$ of 13 animals in the PBD group (Fig 3). No foci were seen in the sham operated animals. The volume density of the acidophilic atypical acinar cell foci was significantly lower in the fundectomy group than in the PBD group (Table II). There was a similar difference in the mean diameter of the acidophilic atypical acinar cell foci. Furthermore, ${ }^{3} \mathrm{H}$-thymidine labelling index of the acidophilic atypical acinar cell foci was significantly lower after fundectomy than after PBD (Table II). Some nodules with a diameter of 4-6 $\mathrm{mm}$ in three of 13 pancreases in the PBD group, but none of those in the fundectomy group, were surrounded by a fibrous capsule and maintained an acinar cell differentiation suggesting adenomatous change (Fig 4). Basophilic atypical acinar cell foci and carcinomas were not found.

\section{Discussion}

In agreement with others, ${ }^{2021}$ we found that PBD induces chronic endogenous hypercholecystokininaemia with pancreatic hyperplasia and hypertrophy. These changes persisted after 14 months at which time acidophilic atypical acinar cell foci and changes consistent with adenoma were also present. Fundectomy caused a persist-
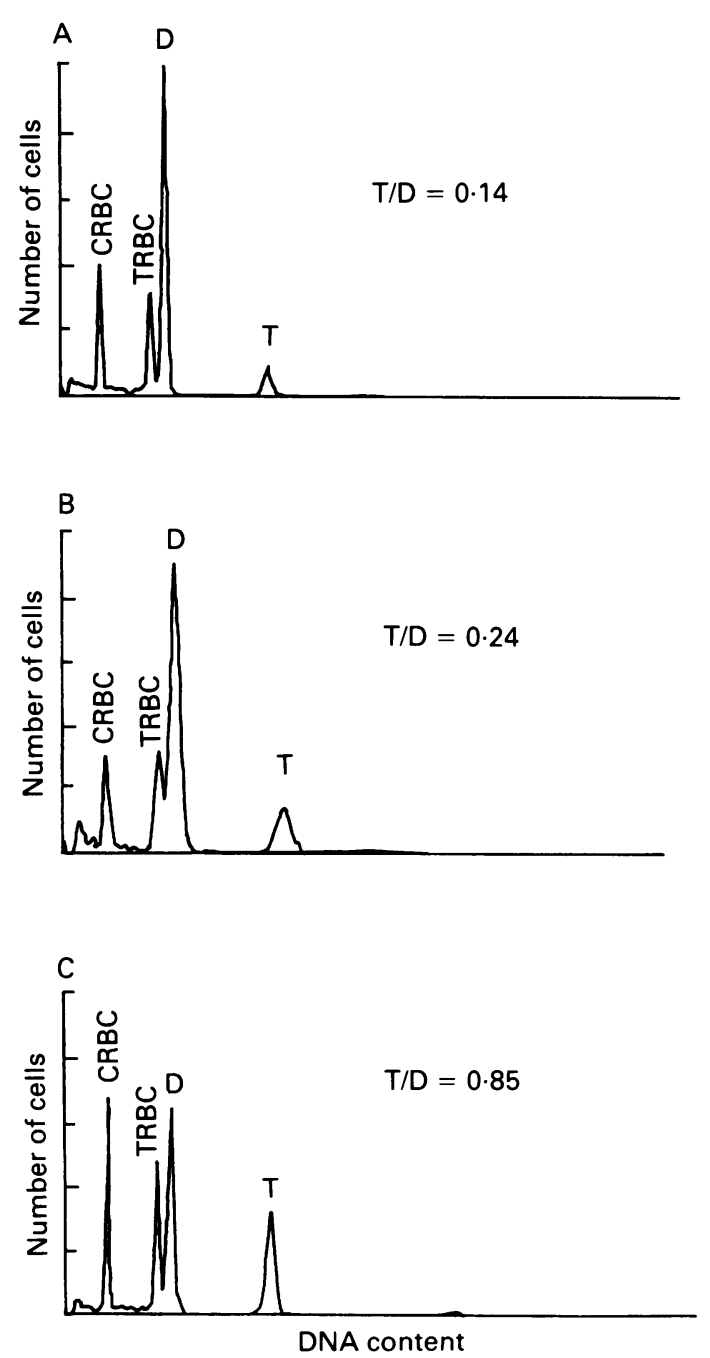

Figure 2: Flow cytometry DNA histograms showing the proportion of tetraploid to diploid nuclei $(T / D)$ in pancreatic tissue from a sham operated $(A)$, a fundectomised $(B)$, and a tissue from a sham operated $(A)$, a fundectomised $(B)$, and a
$P B D$ operated rat $(C)$. The two peaks with the lowest $D N A$ content represent chicken and trout red blood cells (CRBC and $T R B C$, respectively). 


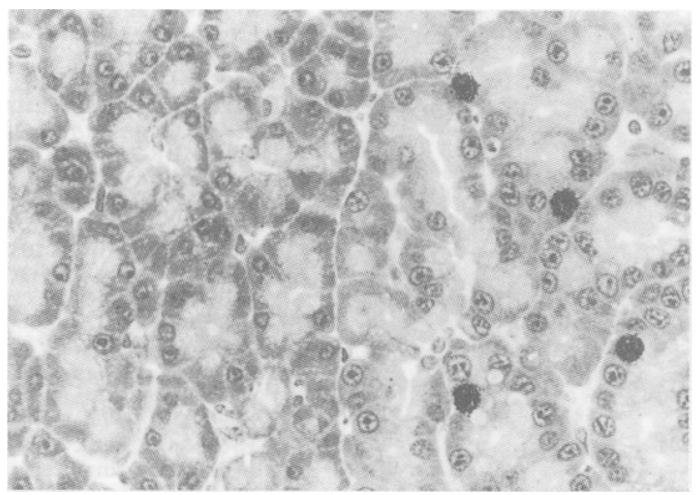

Figure 3: Autoradiographed pancreatic section from a fundectomised rat showing acidophilic atypical acinar cell focus $(a A A C F)$. The cells are large, arranged as acini, and contain a big oval to round nucleus and an intensely eosinophilic granular cytoplasm. The focus is clearly defined from the adjacent pancreas and is not encapsulated. Normal pancreas (left) and aAACF (right). (Haematoxylin and eosin, original magnification $\times 400$ ).

ent endogenous hypergastrinaemia with a significant, although less pronounced, increase in pancreatic weight, total DNA and protein content, and development of acidophilic atypical acinar cell foci. The finding of a more pronounced trophic response and more advanced morphological changes after PBD than after fundectomy was paralleled by a significant increase in the ratio of tetraploid to diploid nuclei in pancreatic tissue.

In a previous study, fundectomy did not result in pancreatic hypertrophy. ${ }^{14}$ Some factors should be considered to find an explanation for the difference between that study and this one. It was recently shown that the trophic response in rat pancreas is inversely related to the age of the animals at the onset of stimulation. ${ }^{36}$ In this aspect there seems to be no difference between the studies. The difference between the study periods, however, was a maximum of 10 weeks in the previous study compared with 14 months in this study. This would correspond to several decades in man. Furthermore, although pancreatic weight, DNA, RNA, and protein contents were analysed in the previous study, results of simultaneous investigations of morphology, morphometry, autoradiography, and DNA flow cytometry were not included. Using a positive control group with PBD, as in this study, was also useful for comparative purposes and in the interpretation of morphological changes in the fundectomy group.

A recent study in rats, which considered effects of gastric resection, showed that pronounced duodenogastric reflux (induced by a split gastrojejunostomy) was associated with

TABLE II Mean (SEM) of the volume density (\%), diameter, and acinar cell ${ }^{3} H$-thymidine labelling index $(L I)$ of acidophilic atypical acinar cell foci $(a A A C F)$ of the pancreas 14 months after fundectomy and pancreaticobiliary diversion $(P B D)$ in the rat.

\begin{tabular}{lllllr}
\hline Groups & $\begin{array}{l}\text { Animals } \\
(\boldsymbol{n})\end{array}$ & $\begin{array}{l}\text { Animals } \\
\text { with } \\
a A A C F\end{array}$ & $\begin{array}{l}\text { aAACF } \\
(\%)\end{array}$ & $\begin{array}{l}\text { Diameter } \\
(\mathrm{mm})\end{array}$ & $\begin{array}{c}\text { LI } \\
(\text { per 1000) }\end{array}$ \\
\hline $\begin{array}{l}\text { Fundectomy } \\
\text { PBD }\end{array}$ & 10 & 4 & $\begin{array}{l}0 \cdot 4(0 \cdot 2) \\
22 \cdot 8(7 \cdot 5)^{\star \star}\end{array}$ & $\begin{array}{l}0.22(0.05) \\
2 \cdot 34(0.61)^{\star \star}\end{array}$ & $27(3)^{\star \star}$ \\
\hline
\end{tabular}

$\star \star \mathrm{p}<0.01$ according to two tailed Mann-Whitney U test. aAACF were not observed in the sham operated controls. hyperplasia and adenoma development in the pancreas after 14 months. ${ }^{37}$ Whether these findings were a result of stagnation of secretions with increased CCK release in the afferent jejunal loop, a changed alkaline gastric content, or both is unclear. There is, however, no reason to believe that fundectomy is associated with increased duodenogastric reflux.

The occurrence of acidophilic atypical acinar cell foci after longstanding fundectomy has not previously been reported. Morphologically, these foci did not differ from those seen in the PBD group of from lesions previously defined as acidophilic atypical acinar cell foci, which may be induced by a chemical carcinogen in rat. ${ }^{27}$ In the sham operated controls, acidophilic atypical acinar cell foci were not detected within an area of the pancreatic tail corresponding to at least 30000 counted points. While some previous studies have shown absence of foci in old, untreated and control rats, ${ }^{20} 21$ others have shown that foci do occur spontaneously with increasing age. ${ }^{38}{ }^{39}$ Neither is contradicted by the results of this study.

Acidophilic atypical acinar cell foci in the rat have a high proliferative capacity and have been shown to be responsive to CCK, whereas the basophilic atypical acinar cell foci seem to have a low growth potential, not appreciably affected by CCK. ${ }^{2738-41}$ This study supports this concept as no basophilic atypical acinar cell foci were seen after longterm PBD. Furthermore, fundectomy does not seem to influence the development or growth of basophilic atypical acinar cell foci.

The ${ }^{3} \mathrm{H}$-thymidine labelling index of the acidophilic atypical acinar cell foci in the fundectomy group was significantly lower than that in the PBD group, showing that PBD has the strongest stimulatory effect. This conclusion is further strengthened by the fact that the pancreatic weight and volume density of the acidophilic atypical acinar cell foci in the fundectomy group were also significantly lower than those in the PBD group.

The fraction of cells in S phase did not differ significantly between the groups. Although being significant, the difference in proliferative activity of the acidophilic atypical acinar cell foci between the fundectomy group and the PBD group may not have been large enough to cause measurable differences in the $S$ phase, especially as flow cytometry was performed on total pancreatic tissue and not on isolated acidophilic atypical acinar cell foci.

We conclude that fundectomy for about half of the life span in rats stimulates pancreatic hyperplasia and hypertrophy as well as growth of acidophilic atypical acinar cell foci. These effects are less pronounced than those of PBD with hypercholecystokininaemia. Although hypergastrinaemia is a prominent feature, it may not be the only or main factor responsible for the pancreaticotrophical effect of fundectomy. Changes in the balance of other hormones or growth factors, which are as yet unknown, may result from fundectomy. Another factor which may be of relevance is the potentially carcinogenic substrate $(\mathrm{N}$-nitrosamines and $\mathrm{N}$-nitrosamides) formed with achlorhydria in the fairly large gastric remnant (rumen and antrum) after 


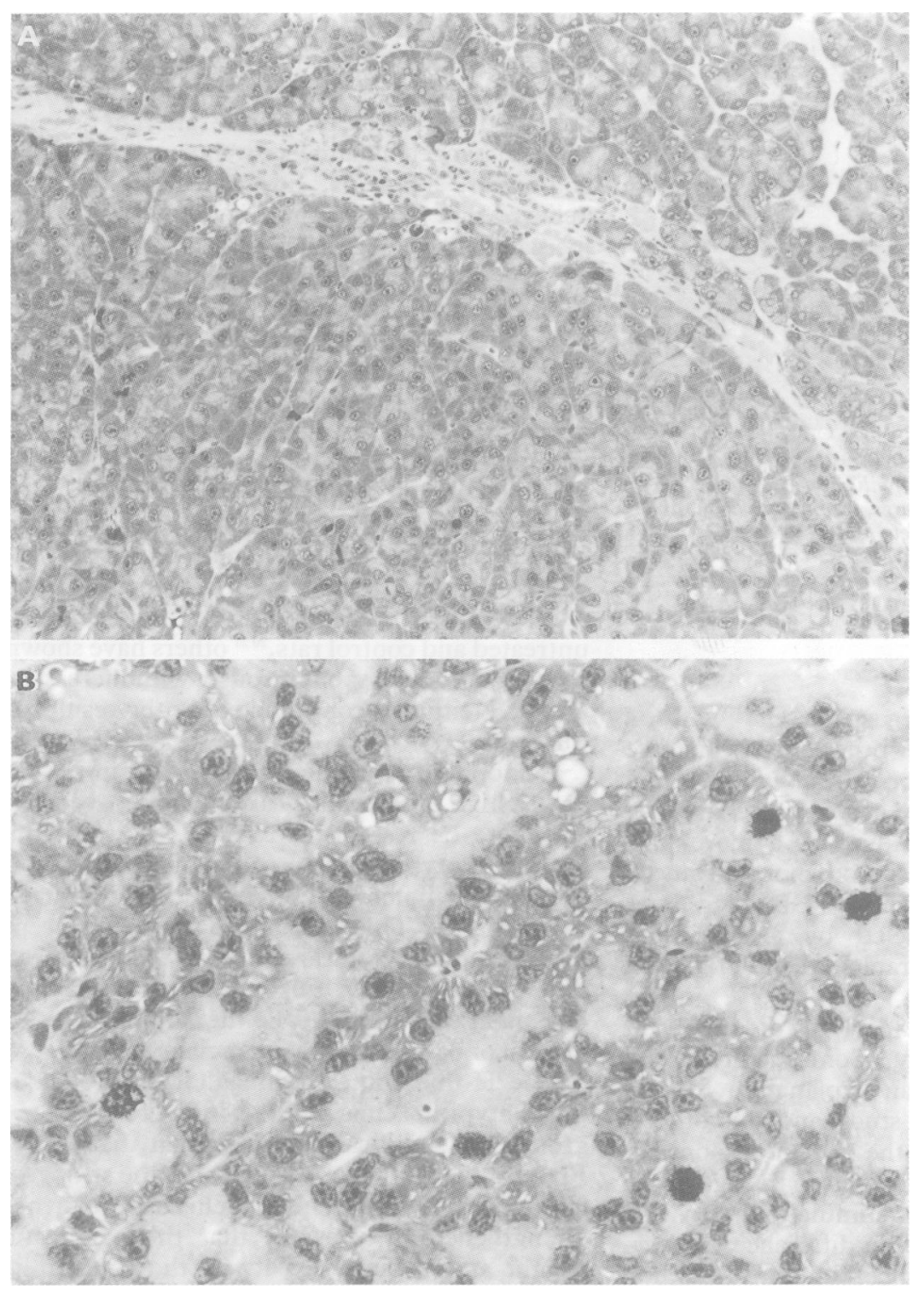

Figure 4: Autoradiographed pancreatic section from a $P B D$ operated rat showing part of a nodule with a mean diameter of $5.4 \mathrm{~mm}$ and surrounding fibrous capsule $(A)$ with an acinar cell differentiation $(B)$, suggestive of adenoma. (Haematoxylin and eosin, $\times 100$ and $\times 400$, respectively).
2 Dembinski AB, Johnson LR. Stimulation of pancreatic growth by secretin, caerulein, and pentagastrin. Endocrinology 1980; 106: 323-8.

3 Solomon TE, Morisset J, Wood JG, Bussjaeger LJ. Additive interaction of pentagastrin and secretin on pancreatic growth in rats. Gastroenterology 1987; 92: 429-35.

4 Johnson LR. Effects of gastrointestinal hormones on pancreatic growth. Cancer 1981; 47: 1640-5.

5 Dembinski AB, Johnson LR. Growth of pancreas and gastrointestinal mucosa in antrectomized and gastrin-treated rats. Endocrinology 1979; 105: 769-73.

6 Reber HA, Johnson F, Deveney K, Montgomery C, Way LW. Trophic effects of gastrin on the exocrine pancreas in rats. F Surg Res 1977; 22: 554-60.

7 Yu DH, Noguchi M, Zhou ZC, Villanueva ML, Gardner JD, Jensen RT. Characterization of gastrin receptors on guine pig pancreatic acini. Am F Physiol 1987; 253: G793-801

8 Scemama JL, Fourmy D, Zahidi A, Pradayrol L, Susini C, Ribet A. Characterization of gastrin receptors on a rat pancreatic acinar cell line (AR42J). A possible model for studying gastrin mediated cell growth and proliferation. $G u$ 1987; 28 (suppl 1): 233-6.

9 Valenzuela JE, Walsh JH, Isenberg JI. Effect of gastrin on pancreatic enzyme secretion and gallbladder emptying in man. Gastroenterology 1976; 71: 409-11.

10 Håkanson R, Blom H, Carlsson E, Larsson H, Ryberg B, Sundler F. Hypergastrinaemia produces trophic effects in stomach but not in pancreas and intestines. Regul Pept 1986; 13: $225-33$.

11 Håkanson R, Axelson J, Ekman R, Sundler F. Hypergastrinemia evoked by omeprazole stimulates growth of gastric mucosa but not of pancreas or intestines in hamster, gastric mucosa but not of pancreas or intestines in ham
guinea pig and chicken. Regul Pept 1988; 23: 105-15.

12 Ryberg B, Axelson R, Håkanson R, Sundler F, Mattsson H Trophic effects of continuous infusion of [ Leu $\left.{ }^{15}\right]$-gastrin-17 in the rat. Gastroenterology 1990; 98: 33-8.

13 Tatsuta $M$, Itoh T, Okuda S, Tamura $H$, Yamamura $H$. Effect of fundusectomy on serum and antral gastrin levels in rats. Gastroenterology 1977; 72: 78-81.

14 Oscarson J, Håkanson R, Liedberg G, Lundquist G, Sundler $F$, Thorell J. Variated serum gastrin concentration: Trophic effects on the gastrointestinal tract of the rat. Acta Physiol Scand 1979; (Suppl 475): 3-27.

15 Miazza BM, Turberg Y, Guillaume P, Hahne W, Chayvialle JA, Loizeau E. Mechanism of pancreatic growth induced by pancreatico-biliary diversion in the rat. Scand $\mathcal{J}$ Gastroenterol 1985; 20 (Suppl 112): 75-83.

16 Dowling RH, Hiazza B Levan $\mathrm{H}$, et al. Hormones and polyamines in intestinal and pancreatic adaptation. Scand $\mathcal{F}$ Gastroenterol 1985; 20 (Suppl pancreatic adap

17 Chu M, Borch K, Lilja I, Blomqvist L, Rehfeld JF, Ihse I Endogenous hypercholecystokininemia model in the hamster: Trophic effect on the exocrine pancreas. Pancrea 1992; 7: 220-5.

18 Axelson J, Håkanson R, Ihse I, Lilja I, Rehfeld JF, Sundler F Effects of endogenous and exogenous cholecystokinin and of infusion with cholecystokinin antagonist L-364,718 on pancreatic and gastrointestinal growth. Scand $\mathcal{F}$ Gastroentero 1990; 25: 471-80.

19 Gasslander T, Axelson J, Håkanson R, Ihse I, Lilja I, Rehfeld JF. Cholecystokinin is responsible for growth of the pancreas following pancreatico-biliary diversion in rats. Scand $\mathcal{F}$ Gastroenterol 1990; 25: 1060-5.

20 Stace NH, Palmer TJ, Vaja S, Dowling RH. Longterm pancreaticobiliry diversion stimulates hyperplastic and adenomatous nodules in the rat pancreas: a new model for spontaneous tumour formation. Gut 1987; 28 (Suppl 1): 265-8.

21 Miazza BM, Widgren S, Chayvialle JA, Nicolet T, Loizeau E. Exocrine pancreatic nodules after longterm pancreaticobiliry diversion in rats. An effect of raised CCK plasma concentrations. Gut 1987; 28 (Suppl 1): 269-73.

fundectomy. Certainly, further investigations aimed to clarify these aspects are warranted. Although these findings were on rats, they may also be relevant with regard to the possible effects of achlorhydria with or without hypergastrinaemia in man. Epidemiological studies have shown that, apart from an increased risk of developing gastric cancer, patients with pernicious anaemia, as well as patients operated on with gastric resection more than 20 years ago, have an increased risk of developing cancer in other digestive organs, including the pancreas. ${ }^{42}$ ${ }^{45}$ It should be emphasised, however, that this study did not show pancreatic neoplasia, including adenoma, in any of the fundectomised animals.

The kind advice of Professor Parviz M Pour on the histologica interpretation is greatly appreciated. The study was supported by grants from the Swedish National Cancer Association, the
Swedish Society of Medicine, and Cancer funds of Östergötland County, Sweden.

I Balas D, Senegas-Balas F, Pradayrol L, Vayssette J, Bertrand C, Ribet A. Long-term comparative effect of cholecysto, Ribet A. Long-term comparative effect of cholecysto-
kinin and gastrin on mouse stomach, antrum, intestine, and exocrine pancreas. Am $\mathcal{F}$ Anat 1985; 174: 27-43.
. DNA analysis. Cytometry 1983; 3: 323-7.

23 Labarca C, Paigen K. A simple, rapid and sensitive DNA assay procedure. Anal Biochem 1980; 102: 344-52.

24 Lowry OH, Rosebrough NJ, Farr AL, Randall RJ. Protein measurement with the folin phenol reagent. $7 \mathrm{Biol}$ Chem 1951; 193: 265-75.

25 Vindeløv LL, Christensen IJ, Nissen NI Standardization of high-resolution flow cytometric DNA analysis by the simultaneous use of chicken and trout red blood cells as internal taneous use of chicken and trout red blood cells

26 Baisch H, Beck H-P, Christensen IJ, Hartmann NR, Fried J Dean PN, et al. Comparison of evaluation methods for DNA hean PN, et al. Comparison of evaluation methods for DNA histograms me

27 Rao MS, Upton MP, Subbarao V, Scarpelli DG. Two populations of cells with differing proliferative capacities in atypica acinar cell foci induced by 4-hydroxyaminoquinoline-1 oxide in the rat pancreas. Lab Invest 1982; 46: 527-34.

28 Longnecker DS. Early morphologic markers of carcinogenicity in rat pancreas. Environ Sci Res 1983; 29: 43-60.

29 Longnecker DS, Roebuck BD, Yager JD, Lilja HS, Siegmund AB. Pancreatic carcinoma in azaserine-treated rats: induction, classification and dietary modulation incidence. Cancer 1981; 47: 1562-72.

30 Weibel ER, Kistler GS, Scherle WF. Practical stereological methods for morphometric cytology. $\mathcal{f}$ Cell Biol 1966; 30: methods.

31 Rehfeld JF, Stadil F, Rubin F. Production and evaluation of antibodies for the radioimmunoassay of gastrin. Scand $\mathcal{F}$ Clin Lab Invest 1972; 32: 221-32. method for the preparation of nuclei for flow cytometric 
32 Rehfeld JF. Gastrins in serum. Scand F Gastroenterol 1973; 8:

33 Rehfeld JF. Immunochemical studies on cholecystokinin. I Development of sequence-specific radioimmunoassays for porcine triacontatriapeptide cholecystokinin. $7 \mathrm{Biol}$ Chem 1978; 253: 4016-21

34 Byrnes DJ, Henderson L, Borody T, Rehfeld JF. Radioimmunoassay of cholecystokinin in human plasma. Clin Chim Acta 1981; 111: 81-9.

35 Cantor P. Evaluation of a radioimmunoassay for cholecystokinin in human plasma. Scand $\mathcal{F}$ Clin Lab Invest 1986; 46 : 213-21.

36 Poston GJ, Saydjari R, Lawrence JP, Chung D, Townsend $\mathrm{CM} \mathrm{Jr}$, Thompson JC. Aging and the trophic effects of cholecystokinin, bombesin and pentagastrin on the rat pancreas. Pancreas 1991; 6: 407-11.

37 Taylor PR, Dowling RH, Palmer TJ, Hanley DC, Murphy $\mathrm{GM}$, Mason RC, et al. Induction of pancreatic tumours by longterm duodenogastric reflux. Gut 1989; 30: 1596-600.

38 Roebuck BD, Baumgartner KJ, Thron CD. Characterization of two populations of pancreatic atypical acinar cell foci induced by azaserine in the rat. Lab Invest 1984; 50: 141-6.

39 Douglas BR, Woutersen RA, Jansen JBMJ, Jong AJL, Rovati LC. Influence of cholecystokinin antagonist on the effects of cholecystokinin and bombesin on azaserine-induced lesions in rat pancreas. Gastroenterology 1989; 96: 462-9.

40 Lhoste EF, Longnecker DS. Effect of bombesin and caerulein on early stages of carcinogenesis induced by azaserine in the rat pancreas. Cancer Res 1987; 47: 3273-7.

41 Stewart ID, Flaks B, Watanapa P, Davies PW, Williamson RCN. Pancreatobiliary diversion enhances experimental pancreatic carcinogenesis. Brf Cancer 1991; 63: 63-6.

42 Caygill C, Hill M, Craven J, Hall R, Miller C. Relevance of gastric achlorhydria to human carcinogenesis. In: O'Neill IK, von Borstel RC, Miller CT, Long J, Bartsch $\mathrm{H}$, eds. $N$-nitroso compounds: occurrence, biological effects and relevance to human cancer. No 57. Lyon: International Agency for Research on Cancer, 1984: 895-900.

43 Borch K, Kullman E, Ledin T, Ihse I. Increased incidence of pancreatic neoplasia in pernicious anemia. World $\mathcal{f}$ Surg 1988; 12: 866-70.

44 Talley NJ, Chute CG, Larson DE, Epstein R, Lydick EG, Melton LJ. Risk of colorectal adenocarcinoma in pernicious anemia. Ann Intern Med 1989; 111: 738-42.

45 Caygill CPJ, Hill MJ, Hall CN, Kirkham JS, Northfield TC. Increased risk of cancer at multiple sites after gastric surgery for peptic ulcer. Gut 1987; 28: 924-8. 